\title{
PENGARUH PELATIHAN TERHADAP KINERJA KARYAWAN PADA PT SARANA MEDIA TRANSINDO DI JAKARTA
}

\author{
${ }^{1 *}$ Ridwan Fahrozi, ${ }^{2}$ Rasfiuddin Sabaruddin, ${ }^{3}$ Dodi Ilham, ${ }^{4}$ Novingky Ferdinand, \\ ${ }^{5}$ Sawqi Saad El Hasan \\ 1,2STIE Hidayatullah, Depok, Jawa Barat, Indonesia \\ ${ }^{3}$ IAIN Palopo, Kota Palopo, Sulawesi Selatan, Indonesia \\ 4.5STEBIS Bina Mandiri, Bogor, Jawa Barat, Indonesia \\ rridwan@stiehidayatullah.ac.id
}

\begin{abstract}
Abstrak
Penelitian ini bertujuan untuk mengetahui pengaruh pelatihan terhadap kinerja karyawan pada PT. Sarana Media Transindo di Jakarta. Metode yang digunakan adalah explanatory research dengan sampel sebanyak 73 responden. Teknik analisis menggunakan analisis statistik dengan pengujian regresi, korelasi, determinasi dan uji hipotesis. Hasil penelitian ini variabel pelatihan diperoleh nilai rata-rata skor sebesar 3,807 dengan kriteria baik. Variabel kinerja karyawan diperoleh nilai rata-rata skor sebesar 3,877 dengan kriteria baik. Pelatihan berpengaruh positif dan signifikan terhadap kinerja karyawan dengan nilai persamaan regresi $Y=13,351+0,668 X$, dan nilai koefisien korelasi 0,785 atau memiliki tingkat hubungan yang kuat dengan nilai determinasi $61,7 \%$. Uji hipotesis diperoleh signifikansi $0,000<0,050$.
\end{abstract}

Kata Kunci: Pelatihan, Kinerja Karyawan

\begin{abstract}
This study aims to determine the effect of training on employee performance at PT. Transindo Media Facilities in Jakarta. The method used is explanatory research with a sample of 73 respondents. The analysis technique uses statistical analysis with regression, correlation, determination and hypothesis testing. The results of this study of the training variable obtained an average score of 3.807 with good criteria. Employee performance variable obtained an average score of 3.877 with good criteria. Training has a positive and significant effect on employee performance with the value of the regression equation $Y=13,351+0.668 X$, and the correlation coefficient value of 0.785 or has a strong relationship with a determination value of $61.7 \%$. Hypothesis testing obtained a significance of $0.000<0.050$.
\end{abstract}

Keywords: Training, Employee Performance 


\section{PENDAHULUAN}

\section{Latar Belakang}

Sumber daya manusia yang merupakan salah satu faktor yang ikut terlibat secara langsung dalam menjalankan kegiatan perusahaan dan berperang penting dalam meningkatkan kinerja karyawan dalam mencapai tujuan yang telah ditetapkan. Sumber daya manusia dituntut untuk mampu mengatasi segala tantangan dan diharapkan mampu memanfaatkan peluang serta dapat memenuhi tuntutan kebutuhan, khususnya yang ada atau datang dari lingkungan kerjanya.

PT. Sarana Media Transindo merupakan perusahaan swasta yang bergerak dalam bidang Spesialis Instalasi Fiber Optic, CCTV, Media Converter, dan Instalasi Jaringan Kantor. Dengan telah diberlakukannya perdagangan bebas semua pelaku bisnis tidak terkecuali PT. Sarana Media Transindo terus memperkuat pangsa pasar dalam negeri sebagai salah satu langkah menghadapi persaingan global dan ikut memperkuat pertumbuhan industri dalam negeri, maka PT. Sarana Media Transindo bertekad untuk menjadi perusahaan yang konsisten dengan menjaga kualitas sumber daya manusianya sehingga semua aspek yang diperlukan dapat menunjang kinerja dapat dicapai dengan maksimal. Guna menyelaraskan visi dan misi, PT. Sarana Media Transindo harus terus berusaha memperbaiki kemampuan sumber daya manusia sehingga mampu mewujudkan tujuan perusahaan dengan baik.

Kinerja merupakan salah satu komponen yang harus dimiliki oleh suatu lembaga atau perusahaan apabila ingin mencapai tujuan yang telah ditetapkan. Dalam kegiatannya organisasi atau perusahaan harus mampu meningkatkan kinerja dari waktu ke waktu, karena ini menyangkut terhadap kinerja lembaga tersebut. Kinerja yang baik mampu menunjukkan jumlah pencapaian yang meningkat dan memenuhi kualitas pekerjaan yang baik, mampu melakukan tindakan yang mampu menunjang pekerjaan secara optimal, memiliki kepercayaan diri yang baik dalam menyelesaikan pekerjaan, bertanggung jawab sepenuhnya pada tugas dan kewajinannya. Disamping itu karyawan juga memiliki kemampuan dalam mengatasi persoalan dalam pekerjaan sehingga mampu menambah daya saing perusahaan secara baik. Hal tersebut selaras dengan teori Simamora (2017:612) berpendapat "Kinerja kerja merupakan perbandingan antara hasil yang dicapai seseorang dengan target yang ditetapkan dalam waktu tertentu dengan sumber daya yang digunakan".

PT. Sarana Media Transindo menilai kinerja karyawan berdasar padai hasil pengerjaan proyek pemasangan alat CCTV, instalasi baik di gedung maupu di ruko perkantoran dengan membandingkan jumlah target pengerjaan dengan realisasi setiap tahunnya.

Pelatihan sangat diperlukan dalam rangka meningatkan kualitas sumberdaya manusia dalam memajukan perusahaan tersebut, dan merupakan salah satu faktor yang sangat penting dalam persaingan baik dari dalam maupun dari luar negeri, perkembangan keadaan, ilmu pengetahuan dan teknologi yang sangat cepat dalam suatu perusahaan perlu diimbangi dengan upaya pengembangan sumber daya manusia yang berfungsi untuk menangani dan menjalankan roda perusahan tersebut. Penyesuaian kemampuan untuk melaksanakan tugas sesuai dengan standar baru, teknologi baru, dan system prosedur baru yang mendorong setiap perusahaan untuk melaksanakan pelatihan pada para karyawan. Hal tersebut dapat dimengerti, bahwa wahana yang tepat untuk mentransfer segala perkembangan baru yang terjadi di lingkungan perusahaan adalah melalui pelatihan yang berkeseimbangan.

Mengingat pelatihan umumnya berorientasi pada peningkatan skill, 
maka para pelatih yang dipilih untuk memberikan materi pelatihan harus benar benar memiliki kualifikasi yang memadai sesuai bidangnya, Karyawan disamping memiliki tingkat pendidikan yang dipersyaratkan juga harus memiliki kompetensi yang bai. Dari peserta pelatihan juga harus diseleksi berdasarkan persyratan tertentu dan kualifikasi yang sesuai. Demikian pula dengan materi pelatihan SDM harus benar-benar materi yang sesuai dengan tujuan pelatihan SDM. Terkait dengan metode yang digunakan juga akan lebih menjamin berlangsungnya kegiatan pelatihan SDM yang efektif apabila sesuai dengan jenis materi dan komponen peserta pelatihan.

Menurut Rivai (2016:240) adalah proses secara sistematis mengubah tingkah laku pegawai untuk mencapai tujuan organisasi. Pelatihan berkatian dengan keahlian dan kemampuan pegawai untuk melaksanakan pekerjaan saat ini. Pelatihan memiliki orientasi saat ini dan membantu pegawai untuk mencapai kehalian dan kemampuan tertentu agar berhasil dalam melaksanakan pekerjaanya.

Kegiatan pelatihan atau training tetap harus dilaksanakan secara terprogram agar ada peningkatan softskill yang harus dimiliki oleh karyawan itu sendiri, misalnya kemampuan untuk berkomunikasi dengan konsumen, kerjasama team yang solid, jujur, ulet dan percaya diri dalam menyelesaikan suatu pekerjaan dengan disertai oleh sikap pelatihan dan tanggung jawab kerja sehingga kinerja karyawan di perusahaan dapat tercapai secara optimal. Berikut ini gambaran pelaksanaan pelatihan yang pernah dilakukan perusahaan, dimana ada beberapa aspek kegiatan yang kurang tepat seperti metode pelaksanaan maupun materi yang disampaikan sehingga kedepan perlu dilakukan evaluasi agar pelatihan dapat tepat sasaran.
Kegiatan pelatihan atau training tetap harus dilaksanakan secara terprogram agar ada peningkatan softskill yang harus dimiliki oleh karyawan itu sendiri, misalnya kemampuan untuk berkomunikasi dengan konsumen, kerjasama team yang solid, jujur, ulet dan percaya diri dalam menyelesaikan suatu pekerjaan dengan disertai oleh sikap pelatihan dan tanggung jawab kerja sehingga kinerja karyawan di perusahaan dapat tercapai secara optimal

Berdasarkan latar belakang permasalahan diatas, maka penulis tertarik untuk melakukan penelitian lebih lanjut dengan judul: "Pengaruh Pelatihan Terhadap Kinerja Karyawan Pada PT. Sarana Media Transindo di Jakarta ".

\section{Rumusan Masalah}

a. Bagaimana pelatihan pada PT. Sarana Media Transindo di Jakarta?

b. Bagaimana kinerja karyawan pada PT. Sarana Media Transindo di Jakarta.

c. Adakah pengaruh antara pelatihan terhadap kinerja karyawan pada PT. Sarana Media Transindo di Jakarta?

\section{Tujuan Penelitian}

a. Untuk mengetahui kondisi pelatihan pada PT. Sarana Media Transindo di Jakarta.

b. Untuk mengetahui kondisi kinerja karyawan pada PT. Sarana Media Transindo di Jakarta.

c. Untuk mengetahui pengaruh pelatihan terhadap kinerja karyawan pada PT. Sarana Media Transindo di Jakarta.

\section{TINJAUAN PUSTAKA}

\section{Pelatihan}

Yang dimaksud pelatihan menurut Rivai (2016:240) adalah proses secara sistematis mengubah tingkah laku pegawai untuk mencapai tujuan organisasi. Pelatihan berkatian dengan keahlian dan kemampuan pegawai 
untuk melaksanakan pekerjaan saat ini. Pelatihan memiliki orientasi saat ini dan membantu pegawai untuk mencapai kehalian dan kemampuan tertentu agar berhasil dalam melaksanakan pekerjaanya.

\section{Kinerja Karyawan}

Menurut Mangkunegara (2016:75) pengertian kinerja adalah hasil kerja secara kualitas dan kuantitas yang dicapai oleh seorang pegawai dalam melaksanakan tugasnya sesuai dengan tanggung jawab yang diberikan kepadanya.

\section{METODE PENELITIAN}

\section{Populasi}

Yang dijadikan sebagai populasi dalam penelitian ini adalah responden yang berjumlah 73 responden PT. Sarana Media Transindo di Jakarta.

2. Sampel

Teknik pengambilan sampling dalam penelitian ini adalah sampel jenuh, dimana semua anggota populasi dijadikan sebagai sampel. Dengan demikian sampel dalam penelitian ini sampel yang digunakan berjumlah 73 responden.

\section{Jenis Penelitian}

Jenis penelitian yang dipakai adalah asosiatif, dimana tujuannya adalah untuk mengetahui atau mencari keterhubungan antara variabel independen terhadap variabel dependennya

\section{Metode Analisis Data}

Dalam menganalisis data digunakan uji validitas, uji reliabilitas, analisis regresi linier sederhana, analisis koefisien korelasi, analisis koefisien determinasi dan pengujian hipotesis.

\section{HASIL PENELITIAN}

\section{Analisis Deskriptif}

Pada pengujian ini digunakan untuk mengetahui skor minimum dan maksimum skor tertinggi, ratting score dan standar deviasi dari masing-masing variabel. Adapun hasilnya sebagai berikut:

Tabel 1. Hasil Analisis Descriptive Statistics

\begin{tabular}{|l|r|r|r|r|r|}
\hline \multicolumn{7}{|c|}{ Descriptive Statistics } \\
\hline & N & Minimum & Maximum & Mean & Std. Deviation \\
\hline Pelatihan (X) & 73 & 29 & 49 & 38.07 & 4.476 \\
\hline Kinerja Karyawan (Y) & 73 & 30 & 50 & 38.77 & 3.806 \\
\hline Valid N (listwise) & 73 & & & & \\
\hline
\end{tabular}

Pelatihan diperoleh varians minimum sebesar 29 dan varians maximum 49 dengan ratting score sebesar 3,807 dengan standar deviasi 4,476. Skor ini termasuk pada rentang sakala 3,40 4,19 dengan kriteria baik atau setuju. Kinerja karyawan diperoleh varians minimum sebesar 30 dan varians maximum 50 dengan ratting score sebesar 3,877 dengan standar deviasi 4,465. Skor ini termasuk pada rentang sakala 3,40 4,19 dengan kriteria baik atau setuju.
2. Analisis Verifikatif.

Pada analisis ini dimaksudkan untuk mengetahui pengaruh variabel independen terhadap variabel dependen. Adapun hasil pengujian sebagai berikut:

\section{a. Analisis Regresi Linier Sederhana}

Uji regresi ini dimaksudkan untuk mengetahui perubahan variabel dependen jika variabel independen mengalami perubahan. Adapun hasil pengujiannya sebagai berikut:

Tabel 2. Hasil Pengujian Regresi Linier Sederhana

\begin{tabular}{|c|c|c|c|c|c|c|}
\hline \multicolumn{7}{|c|}{ Coefficients $^{a}$} \\
\hline \multirow{2}{*}{\multicolumn{2}{|c|}{ Model }} & \multicolumn{2}{|c|}{ Unstandardized Coefficients } & \multirow{2}{*}{\begin{tabular}{|c|} 
Standardized Coefficients \\
Beta \\
\end{tabular}} & \multirow[b]{2}{*}{$\mathrm{t}$} & \multirow[b]{2}{*}{ Sig. } \\
\hline & & B & Std. Error & & & \\
\hline \multirow[t]{2}{*}{1} & (Constant) & 13.351 & 2.395 & & 5.574 & .000 \\
\hline & Pelatihan $(\mathrm{X})$ & .668 & .062 & .785 & 10.684 & .000 \\
\hline
\end{tabular}


a. Dependent Variable: Kinerja Karyawan (Y)

Berdasarkan hasil pengujian pada tabel di atas, diperoleh persamaan regresi $\mathrm{Y}=13,351+$ 0,668X. Dari persamaan tersebut dijelaskan sebagai berikut:

1) Konstanta sebesar 13,351 diartikan jika pelatihan tidak ada, maka telah terdapat nilai kinerja karyawan sebesar 13,351 point.

2) Koefisien regresi pelatihan sebesar 0,668 , angka ini positif artinya setiap ada peningkatan pelatihan sebesar 0,668 poin maka kinerja karyawan juga akan mengalami peningkatan sebesar 0,668 point.

\section{b. Analisis Koefisien Korelasi}

Analisis koefisien korelasi dimaksudkan untuk mengetahui tingkat kekuatan hubungan dari variabel independen terhadap variabel dependen. Adapun hasil pengujian sebagai berikut:

\begin{tabular}{|c|c|c|c|}
\hline \multicolumn{4}{|c|}{ Correlations $^{b}$} \\
\hline & & Pelatihan (X) & Kinerja Karyawan $(\mathrm{Y})$ \\
\hline \multirow[t]{2}{*}{ Pelatihan $(\mathrm{X})$} & Pearson Correlation & 1 & $.785^{* *}$ \\
\hline & Sig. (2-tailed) & & .000 \\
\hline \multirow[t]{2}{*}{ Kinerja Karyawan $(\mathrm{Y})$} & Pearson Correlation & $.785^{* *}$ & 1 \\
\hline & Sig. (2-tailed) & .000 & \\
\hline \multicolumn{4}{|c|}{ **. Correlation is significant at the 0.01 level (2-tailed). } \\
\hline \multicolumn{4}{|l|}{ b. Listwise $\mathrm{N}=73$} \\
\hline
\end{tabular}

Berdasarkan hasil pengujian diperoleh nilai korelasi sebesar 0,785 artinya pelatihan memiliki hubungan yang kuat terhadap kinerja karyawan.

\section{c. Analisis Koefisien Determinasi}

Analisis koefisien determinasi dimaksudkan untuk mengetahui besarnya persentase pengaruh dari variabel independen terhadap variabel dependen. Adapun hasil pengujian sebagai berikut:

Tabel 4. Hasil Pengujian Koefisien Determinasi Pelatihan Terhadap Kinerja Karyawan

\begin{tabular}{|l|c|r|r|r|}
\hline \multicolumn{5}{|c|}{ Model Summary } \\
\hline Model & $\mathrm{R}$ & R Square & Adjusted R Square & Std. Error of the Estimate \\
\hline 1 & $.785^{\mathrm{a}}$ & .617 & .611 & 2.374 \\
\hline a. Predictors: (Constant), Pelatihan $(\mathrm{X})$ \\
\hline
\end{tabular}

Berdasarkan hasil pengujian diperoleh nilai determinasi sebesar 0,617 artinya pelatihan memiliki kontribusi pengaruh sebesar 61,7\% terhadap kinerja karyawan, sedangkan sisanya sebesar $38,3 \%$ dipengaruhi oleh faktor lain yang tidak dilakukan penelitian.

\section{d. Uji Hipotesis}

Pengujian hipotesis dengan uji t digunakan untuk mengetahui hipotesis mana yang diterima.

Rumusan hipotesis: Terdapat pengaruh yang signifikan pelatihan terhadap kinerja karyawan.

Tabel 5. Hasil Uji Hipotesis Kegiatan Pelatihan Terhadap Kinerja Karyawan

\begin{tabular}{|c|c|c|c|c|c|c|}
\hline \multicolumn{7}{|c|}{ Coefficients $^{a}$} \\
\hline \multirow{2}{*}{\multicolumn{2}{|c|}{ Model }} & \multicolumn{2}{|c|}{ Unstandardized Coefficients } & \multirow{2}{*}{\begin{tabular}{|c|} 
Standardized Coefficients \\
Beta \\
\end{tabular}} & \multirow[b]{2}{*}{$\mathrm{t}$} & \multirow[b]{2}{*}{ Sig. } \\
\hline & & B & Std. Error & & & \\
\hline \multirow[t]{2}{*}{1} & (Constant) & 13.351 & 2.395 & & 5.574 & .000 \\
\hline & Pelatihan (X) & .668 & .062 & .785 & 10.684 & .000 \\
\hline
\end{tabular}


Berdasarkan hasil pengujian pada tabel di atas, diperoleh nilai $t$ hitung $>t$ tabel atau $(10,684>1,984)$, dengan demikian hipotesis yang diajukan bahwa terdapat pengaruh yang signifikan atara pelatihan terhadap kinerja karyawan diterima.

\section{PEMBAHASAN HASIL PENELITIAN}

\section{Kondisi Jawaban Responden Variabel} Pelatihan

Berdasarkan jawaban responden, variabel pelatihan diperoleh ratting score sebesar 3,807 berada di rentang skala 3,40 - 4,19 dengan kriteria baik atau setuju.

\section{Kondisi Jawaban Responden Variabel Kinerja Karyawan.}

Berdasarkan jawaban responden, variabel kinerja karyawan diperoleh ratting score sebesar 3,877 berada di rentang skala 3,40 - 4,19 dengan kriteria baik atau setuju.

\section{Pengaruh Pelatihan Terhadap Kinerja Karyawan}

Pelatihan berpengaruh signifikan terhadap kinerja karyawan dengan persamaan regresi $Y=13,351+0,668 X$, nilai korelasi sebesar 0,785 atau memiliki hubungan yang kuat dengan kontribusi pengaruh sebesar 61,7\%. Pengujian hipotesis diperoleh nilai t hitung $>\mathrm{t}$ tabel atau $(10,684>1,984)$. Dengan demikian hipotesis yang diajukan bahwa terdapat berpengaruh signifikan antara pelatihan terhadap kinerja karyawan diterima.

\section{KESIMPULAN DAN SARAN}

\section{Kesimpulan}

a. Variabel pelatihan diperoleh ratting score sebesar 3,807 berada di rentang skala 3,40 - 4,19 dengan kriteria baik atau setuju.

b. Variabel kinerja karyawan diperoleh ratting score sebesar 3,877 berada di rentang skala $3,40 \quad-\quad 4,19$ dengan kriteria baik atau setuju.

c. Pelatihan berpengaruh signifikan terhadap kinerja karyawan dengan persamaan regresi $Y=13,351+$
0,668X, nilai korelasi sebesar 0,785 atau kuat dan kontribusi pengaruh sebesar $61,7 \%$ sedangkan sisanya sebesar 38,3\% dipengaruhi faktor lain. Uji hipotesis diperoleh nilai t hitung > $\mathrm{t}$ tabel atau $(10,684>1,984)$.

\section{Saran}

a. Metode pelatihan yang digunakan belum sesuai dengan tujuan pelatihan. Untuk lebih baik lagi dalam pelatihan-pelatihan yang akan datang metode maupun sarana atau alat peraga yang digunakan harus sesuai dengan jenis pelatihan sehingga mudah dipahami dan dimengerti karyawan.

b. Kualitas pekerjaan yang Anda lakukan memiliki kualitas yang diharapkan, untuk lebih baik lagi karyawan harus memiliki kemampuan yang baik didalam menjaga kualitas pekerjaan agar sesuai dengan kualitas yang diharapkan oleh perusahaan.

\section{DAFTAR PUSTAKA}

Abdullah. M (2014). Manajemen dan Evaluasi Kinerja Karyawan. Yogyakarta: Penerbit Aswaja Pressindo.

Algifari. (2015). Analisis Regresi untuk Bisnis dan Ekonomi. Yogyakarta: BPFE.

Arikunto, Suharsimi (2014). Prosedur Penelitian Suatu Pendekatan Praktek. Jakarta: Rineka Cipta.

Bangun, Wilson. (2012). Manajemen Sumber Daya Manusia. Jakarta: Erlangga

Bejo Siswanto (2013) Manajemen Tenaga Kerja Rancangan dalam Pendayagunaan dan Pengembangan Unsur Tenaga Kerja. Bandung: Sinar Baru.

Kustini, E., et al (2021). Pengaruh Keterampilan Kerja Dan Lingkungan Kerja Terhadap Kinerja Karyawan Pada PT. Garuda Daya Pratama Sejahtera (Garuda Indonesia Group). Jurnal Ilmiah PERKUSI, 1(3), 305-314.

Dessler, G. (2006.). Manajemen Sumber Daya Manusia. Jilid II. Jakarta: Indeks.

Edi Sutrisno (2016). Manajemen Sumber Daya Manusia. Jakarta: Prenadamedia 
Group.

George Terry R \& Rue, Leslie W. Rue (2016). Dasar-Dasar Manajemen. Jakarta Bumi Aksara.

Gerry Dessler (2016). Human Resources Management. Prenticehall. London: International Inc.

Handoko (2016). Manajemen Personalia dan Sumberdaya Manusia. Yogyakarta: BPFE.

Hasibuan, Malayu S.P. (2016). Manajemen Sumber Daya Manusia. Edisi Revisi. Jakarta: PT Bumi Aksara.

Imam Ghozali (2017). "Aplikasi Analisis Multivariate Dengan Program SPSS". Edisi Kelima. Semarang: Badan Penerbit Undip.

Istijanto (2014) "Riset Sumber Daya Manusia”. Jakarta: PT. Gramedia Pustaka

Luthans Fred (2014). Organizational Behavior. Ney York: McGraw-Hill. New York.

Mangkunegara, Prabu Anwar. (2016). Evaluasi Kinerja SDM. Cetakan ke tujuh, PT Refika Aditama: Bandung.
Rao, Purba, (2012). Measuring Consumer Perceptions Through Factor Analysis. The Asian.

Robbins, P.S, \& Judge, A.T. (2003). Organizational Behavior. Jakarta: Salemba Empat.

Santoso, Singgih (2015). Menguasai Statistik Multivariat. Jakarta: PT Elex Media Komputindo.

Sedarmayanti (2016) Manajemen Sumber Daya Manusia, Reformasi Birokrasi dan Manajemen Karyawan Negeri Sipil, Cetakan Kelima, Bandung: PT Refika Aditama.

Sudjana (2014). Metode Statistika. Bandung: Tarsido.

Sugiyono (2017). Metode Penelitian Administrasi dilengkapi dengan Metode $R \& D$. Bandung: Alfabeta.

Veithzal Rivai (2015) Manajemen Sumber Daya Manusia Untuk Perusahaan. Jakarta: Raja Grafindo Persada.

Wibowo (2015). Manajemen Kinerja. Jakarta: PT. Raja Grafindo Persada. 